\title{
STUDENT-TEACHERS' ATTITUDES TOWARD STUDENTS WITH DISABILITIES: ASSOCIATIONS WITH CONTACT AND EMPATHY
}

\author{
Jason J. Barr ${ }^{1}$ \\ 'Associate Professor Monmouth University School of Education, USA
}

\begin{abstract}
There is little research on student-teachers' attitudes and contact with students with disabilities, and even fewer researchers have investigated student-teachers' empathy. This study investigated the association between student-teachers' contact with students with disabilities and their attitudes toward students with disabilities as well as the association between student-teachers' attitudes toward students with disabilities and their level of empathy. Student-teachers' contact with students with disabilities was not associated with their attitudes toward students with disabilities. However, higher student-teacher empathy was associated with attitudes that were more positive toward students with disabilities. While most educators would agree that future teachers should be exposed to as many diverse students as possible, this study points to an interpersonal quality that may play a more vital role in shaping future teachers' attitudes toward students with disabilities. This affects how we prepare future teachers and highlights the need for empathy training for future teachers.
\end{abstract}

Keywords: Empathy, Disabilities, Student-teachers, Attitudes, Contact.

Received: 18 November 2013/ Revised: 27 November 2013/ Accepted: 29 November 2013/ Published: 2 December 2013

\section{INTRODUCTION}

Society often considers individuals with disabilities as deviant from individuals without disabilities because they fail to fit the description of normalcy construed by beauty, attractiveness, and able-bodiedness (Seo and Chen, 2009). When society labels a particular group as unfavorably, an individual in that group will likely encounter hindrances imposed on them as he or she strives for personal goals and acceptance into society (Smart, 2008). Therefore, with more students with disabilities being educated in regular education classrooms, there is a need to examine the attitudes that future teachers hold toward students with disabilities. While some research has investigated teachers' attitudes toward students with disabilities, little research has investigated student-teachers' attitudes and contact with students with disabilities, and even fewer have investigated student-teachers' empathic functioning. This study looked at student-teachers' 
contact with three different types of disabilities: physical, developmental, and behavioral. This study also took a multidimensional approach of attitudes toward students with disabilities and studied how contact with different types of disabilities affected three different attitude variables: hopelessness, optimism, and misconceptions. It is important to compare how contact with different disabilities influences different attitudes especially since children with all types of disabilities are being educated in a variety of classroom types. Finally, student-teachers' empathy was investigated and how this related to their attitudes toward students with disabilities.

\subsection{Teacher Attitudes toward Students with Disabilities}

The attitudes of others have important influences on individuals with disabilities (Yuker, 1994). Negative attitudes toward groups of individuals are thought to result in discriminatory behavior and stereotypical responses toward these individuals (Hunt and Hunt, 2000), and research suggests that individuals with disabilities are aware of this differential treatment (Abbott and McConkey, 2006). This may lead individuals with disabilities to experience negative selfevaluations, feelings of powerlessness, and frustration (Jahoda and Markova, 2004). However, positive attitudes can facilitate the inclusion and acceptability of such individuals (Findler et al., 2007). Researchers have identified teachers' attitudes toward students with disabilities as a critical variable in the success of managing children with special needs (Bacon and Schultz, 1991) and in the successful integration of these students into the regular classroom (Stewart, 1990).

Research suggests that teachers in general have positive attitudes toward students with disabilities although many teachers tend to be more indifferent and rejecting toward their students with disabilities (Cook et al., 2007). Scruggs and Mastropieri (1996) found that most teachers supported the idea of inclusion, but only a small percentage demonstrated an openness to include students with disabilities in their own classrooms. Interestingly, as in-service teachers gained more experience they showed increased acceptance of students with disabilities (Cook, 2004) but decreased willingness to teach such students (Burke and Sutherland, 2004). Teachers cited issues of time, effort, the effects on students without disabilities, and their own inadequacies. Berry (2008) found that many teachers were concerned with issues of equity; that they would be unable to meet the needs of all students in their classroom. Conte (1994) found that $50 \%$ of inservice teachers believed that having students with disabilities in the regular classroom would hinder the performance of the other students. Barr and Bracchitta (2008) found that preservice teachers had the most positive attitudes toward students with physical disabilities and the least positive attitudes toward students with developmental disabilities while Hastings and Oakford (2003) found teachers were less willing to include those with emotional and behavioral disorders.

Tait and Purdie (2000) argued the importance of preservice teachers developing positive attitudes toward students with disabilities early in their professional development. However, relatively few researchers have examined the attitudes that student-teachers hold toward individuals with disabilities. Past studies have treated attitudes toward individuals with disabilities as a single, broad category. In the current study, a multidimensional approach to student-teachers' attitudes toward individuals with disabilities was taken. We need 
Multidimensional measures of attitudes to consider attitude variation (McCaughey and Strohmer, 2005). Therefore, this study investigated three different attitudinal variables: hopelessness, optimism, and misconceptions.

\subsection{Teacher Contact with Students with Disabilities}

One important factor to consider when investigating attitudes toward individuals with disabilities is the amount of contact one has had with such individuals (Yuker, 1994) and it is well supported that increased contact promotes more favorable attitudes toward individuals with disabilities (Hunt and Hunt, 2000). Allport (1954) noted that contact between social groups might decrease prejudice. Subsequent research has found varying degrees of support for Allport's intergroup contact theory. Pettigrew and Tropp (2006) conducted a meta-analysis of over 500 studies on intergroup contact theory (involving multiple groups; not just groups with disabilities) and concluded that contact alone is sufficient for greater understanding between groups. Seo and Chen (2009) found that adults who reported favorable attitudes toward individuals with disabilities also reported having greater contact with these individuals. Similar results were found for adolescents (McDougall et al., 2004) and children (Kalyva and Agaliotis, 2009).

Policy mandates that all public school students in grades $\mathrm{P}-12$ classified with a disability be educated in the least restrictive environment. The $30^{\text {th }}$ Annual Report to Congress (US Department of Education, 2008) reported that 95\% of students aged 6 through 21 with a disability were educated in regular classrooms for at least some portion of the school day. From 2000 through 2006, the percentage of students aged six through 21 with a disability who were educated in regular classes for most of the school day ( $80 \%$ or more of the school day) increased from 46.5 percent to 53.7 percent. With more students with disabilities being educated in regular education classrooms, the attitudes future teachers hold toward such students is paramount.

How teachers relate to teaching students with disabilities is influenced by their experiences (Brownlee and Carrington, 2000) and greater contact between student-teachers and students with disabilities is likely to improve student-teachers' attitudes (Jones et al., 1990). Brandes and Crowson (2009) found that preservice teachers with more personal discomfort toward individuals with disabilities in general were more likely to hold negative attitudes toward students with disabilities and to be less supportive of inclusive classroom practices, while preservice teachers with past experiences with individuals with disabilities have more positive attitudes toward such individuals (Tait and Purdie, 2000) and more positive attitudes toward mainstreaming students with disabilities in schools (Harvey and Green, 1984).

Many of the studies performed in the past have treated contact as a broad, one-dimensional category. Thomas (2001) stressed that a single, generalized attitude toward individuals with disabilities ignores the vast differences among them. In a review of over 20 studies, it was determined that the more detailed the assessment of contact, the more likely the study was to find significant relationships between contact and attitudes (Makas, 1993). In the current study, a multidimensional approach to student-teachers' contact with students with disabilities was taken. Being able to measure more than one dimension of contact toward individuals with disabilities 
would help us better understand differences in attitudes that people hold toward such individuals (Pruett et al., 2008). Therefore, this study measured student-teachers' contact with students with three different types of disabilities: physical, developmental, and behavioral. It is important to compare how contact with different disabilities influences different attitudes, especially because children with all types of disabilities are being educated in a variety of classroom settings.

Murphy (1996) claimed that if teachers complete preservice education programs without having developed positive attitudes toward individuals with disabilities, their attitudes will be difficult to change and will not maximize positive outcomes for students with disabilities. However, an important consideration is the distinction between the quantity of contact versus the quality of contact with individuals with disabilities. McManus et al. (2010) found that greater quality of contact uniquely predicted positive attitudes toward individuals with disabilities while greater quantity of contact and increased knowledge of disabilities did not predict positive attitudes. Many teacher preparation programs have focused on the quantity of contact attempting to expose future teachers to as many diverse student populations as possible. However, one could argue that the number of hours spent with students with disabilities might not improve attitudes if the student-teacher does not have the capacity to respond appropriately to students with disabilities, which in turn would strain such interactions. Therefore, it is important to also investigate student-teachers' capacity for or disposition of appropriate responding to students. Hence, empathy becomes a variable of unique importance to understanding student-teachers' attitudes toward students with disabilities.

\subsection{Teacher Empathy}

Empathy is an affective response that stems from the apprehension or comprehension of another's emotional state or condition, feeling similar to what the other person is feeling or would be expected to feel (Eisenberg and Fabes, 1999). Empathy is an integral means of knowing and relating to others (Eisenberg and Müssen, 1989) and adds to the quality of life and the richness of social interactions (Hoffman, 2000). Empathy seems to play a key role in the development of social understanding and positive social behaviors (Schultz et al., 2003) and serves as the foundation for relationships and provides a basis for coping with stress and resolving conflict (Kremer and Dietzen, 1991). Hoffman asserts, "Empathy is the spark of human concern for others, the glue that makes social life possible" (Hoffman, 2000).

Teacher empathy is the ability to express concern and take the perspective of a student, and it involves cognitive and affective domains of empathy (Tettegah and Anderson, 2007). Few researchers have investigated the role of empathy in the everyday school experiences of educators and those planning to become teachers (Tettegah, 2007) even though empathy is an important disposition for educators to possess in order to facilitate positive interactions among students (Good and Brophy, 2000). Both experienced teachers and preservice teachers agree about the importance of empathy in the learning relationship although high student-to-teacher ratios and lack of time constrained the ability of many teachers to show empathy (Cooper, 2010). 
Students who perceive little empathy from their teacher may avoid them, because as children mature they are more selective in their social relationships, choosing to be around those who make them feel good about themselves(Fredrickson and Carstensen, 1990). This could explain why college-age students reported that the most negative experiences in their lives involved teachers more often than any other person (Branan, 1972). Students' perception of their teachers' empathy has been found to influence academic motivation (Branwhite, 1988) and has been found to influence the development of empathy in children (Hoffman, 2000). Empathic abilities have been found to be a strong predictor in whether preservice teachers (Bauman and Del Rio, 2006) and in-service teachers (Yoon, 2004)will intervene in a bullying situation and is a predictor of teachers holding a positive perception of their school's culture (Barr, 2011). Wentzel (1997) found that caring teachers were those who demonstrated democratic interaction styles, developed expectations for students on an individual level, and modeled a caring attitude toward their own work. Overall, the research demonstrates a relationship between empathic abilities and effective teaching from elementary through high school.

Empathy may be best considered as a set of related constructs including both emotional and cognitive components (Davis, 1983). The cognitive components have focused on perspective taking, an individual's ability to view situations from a third-person perspective by taking account of one's own and others' subjective perspectives (Eisenberg, 1990). The emotional components include feelings of warmth, compassion, and concern for others (Davis, 1983). A third aspect of empathy, personal distress, is a self-focused, aversive, affective reaction to the apprehension of another's situation (Batson, 1991), which is believed to result in the desire to avoid contact with the needy or distressed person if possible (Eisenberg and Fabes, 1999). To understand how student teachers' empathic functioning is associated with their attitudes toward students with disabilities, this study looked at all emotional and cognitive constructs of empathy: perspective taking, emotional concern, and personal distress.

\subsection{Current Study}

Little research has investigated student-teachers' attitudes toward and the amount of contact with students with disabilities and no research has investigated the influence of student-teachers' empathy on these variables. This research sought to answer two research questions. First, is there a relationship between the amount of contact student teachers have with students with disabilities and their attitudes toward such students? The first hypothesis is that increased contact with students with disabilities will be associated with increased positive attitudes toward students with disabilities. Specifically, increased contact with students with physical, developmental, and behavioral disabilities will be associated with lower misconceptions, lower hopelessness, and higher optimism. Second, is there a relationship between student teachers' attitudes toward students with disabilities and their level of empathic functioning? The second hypothesis is that increased empathic functioning will be associated with increased positive attitudes toward students with disabilities. Specifically, increased perspective taking, increased 
emotional empathy, and decreased personal distress will be associated with lower misconceptions, lower hopelessness, and higher optimism.

\section{METHODS}

\subsection{Participants}

All participants were graduating student-teachers who had successfully completed their onesemester student teaching experience. All participants were graduating from the same university located in a diverse US suburb. One hundred and eighty-one graduating student teachers voluntarily participated in the study while also completing other surveys required by the university to receive their teaching certification. All participants completed an informed consent. One hundred and forty (112 female, 28 male) student-teachers participated for a $77 \%$ response rate. The student-teachers had a mean age of 24 years $(S D=4.16)$. Ninety-one student-teachers were majoring in regular education and the remaining 49 were majoring in special education. Seventy-four were seeking elementary education certification, 48 were seeking secondary education certification, and the remaining 18 were seeking K-12 certification.

\subsection{Materials}

Participants completed the Scale of Attitudes toward Disabled Persons (SADP; (Antonak, 1982). The SADP consists of 24 Likert-scale items with values ranging from 1 (I disagree very much) to 6 (I agree very much). The original factor analysis of the SADP supported a threefactor solution (Antonak, 1982): optimism, misconceptions, and hopelessness. The first subscale, optimism, measures positive, optimistic views of individuals with disabilities as well as statements affirming the human rights of individuals with disabilities to live in the mainstream of society. The second subscale, misconceptions, measures common misconceptions about the behavior of individuals with disabilities. The third subscale, hopelessness, measures negative, pessimistic beliefs about the educability, maturity, and morality of individuals with disabilities. (Antonak, 1982) reported Cronbach's alpha as .88. In the current study, Cronbach's alpha was .77.

Participants' contact with students with disabilities was determined by answers to three questions designed for this study. The questions determined how much contact participants had with students with physical, developmental, or behavioral disabilities during their student teaching experience. The definitions of physical, developmental, and behavioral disabilities were implicit so participants could include individuals who they felt belonged in a particular category. For each disability category, participants answered each question on a 7-point scale ranging from "No Contact" (0) to "Constant" (6). Cronbach's alpha for the entire scale was .68.

Participants' empathy was measured with The Interpersonal Reactivity Index (Davis, 1980), which is a 28-item Likert-scale consisting of three subscales each taping some concept of empathy. Items range from one (does not describe me well) to five (describes me very well). The perspective-taking subscale assesses the tendency to spontaneously adopt the psychological point of view of others. The emotional concern subscale assesses other-oriented feelings of concerns. The personal distress subscale measures self-oriented feelings of personal anxiety and unease in 
tense interpersonal settings. (Davis, 1980) reported Cronbach's alpha as .74. In the current study, Cronbach's alpha was .68.

\section{RESULTS}

First, demographic differences were explored in the data. Effect sizes were calculated with Cohen's $d$. First, differences in empathy were explored. Females were significantly higher than males in emotional concern, $t(138)=6.35, p<.01, d=1.34$, and in perspective taking $t(138)=$ $2.23, p<.05, d=.47$, but no difference was found in personal distress $t(138)=1.67, p=.09$. There were no differences in empathy between student teachers seeking their certification in elementary, secondary or K-12 or between those majoring in regular education and those majoring in special education. Second, differences in attitudes toward individuals with disabilities were explored. There were no differences in misconceptions, optimism, or hopelessness between genders, between those seeking their certification in elementary, secondary or K-12 or between those majoring in regular education and those majoring in special education. Finally, differences in the amount of contact student teachers had with students with disabilities were explored. Studentteachers majoring in special education had significantly more contact with students with developmental disabilities, $t(138)=2.63, p<.05, d=.56$, and with students with behavioral disabilities, $t(138)=1.88, p=.05, d=.40$, but no difference was found in contact with students with physical disabilities, $t(138)=.58, p=.56$. There were no differences in the amount of contact with students with disabilities between genders or between those seeking their certification in elementary, secondary, or K-12.

To test the first hypothesis, that increased contact with students with disabilities will be associated with increased positive attitudes toward students with disabilities, a series of partial correlations controlling for students' major (regular vs. special education) were conducted to examine the relationship between student-teachers' contact with and attitudes toward students with disabilities. Effect sizes were calculated with $R^{2}$. Student-teachers' attitudes were correlated with their self-reported contact with students with physical, behavioral, and developmental disabilities during their student teaching experience. Results are in Table 1 below.

Table- 1.Correlations between contact and attitudes controlling for major

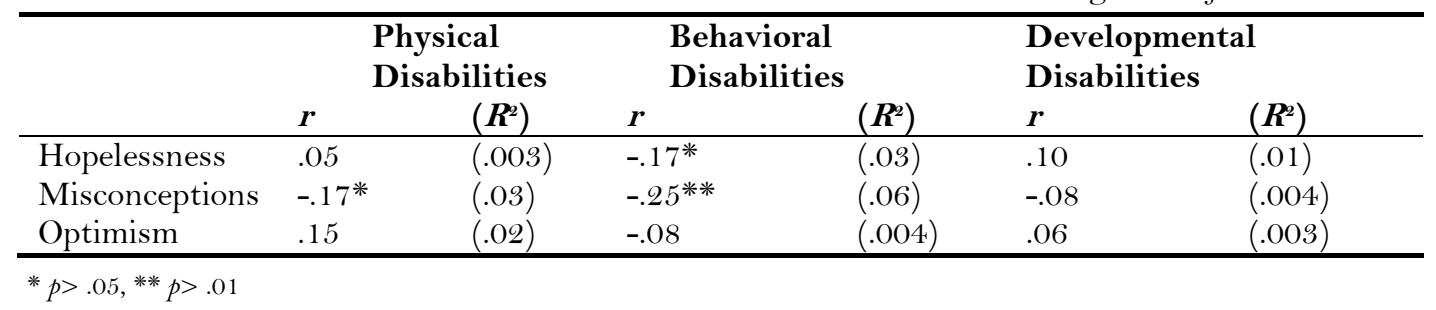

To test the second hypothesis, that increased empathic functioning will be associated with increased positive attitudes toward students with disabilities, a series of partial correlations controlling for gender were conducted to examine the relationship between student-teachers' 
empathy and attitudes toward students with disabilities. Effect sizes were calculated with $R^{2}$. Results are in Table 2 below.

Table- 2.Correlations between empathy and attitudes controlling for gender

\begin{tabular}{lllllll}
\hline & \multicolumn{2}{l}{ Perspective Taking } & \multicolumn{2}{l}{ Emotional Concern } & \multicolumn{2}{l}{ Personal Distress } \\
& $\boldsymbol{r}$ & $\left(\boldsymbol{R}^{2}\right)$ & $\boldsymbol{r}$ & $\left(\boldsymbol{R}^{2}\right)$ & $\boldsymbol{r}$ & $\left(\boldsymbol{R}^{2}\right)$ \\
\hline Hopelessness & $-.32^{* *}$ & $(.10)$ & $-.47^{* *}$ & $(.22)$ & $.27^{* *}$ & $(.07)$ \\
Misconceptions & $-.38^{* *}$ & $(.14)$ & $-.37^{* *}$ & $(.14)$ & $.21^{*}$ & $(.04)$ \\
Optimism & $.31^{* *}$ & $(.10)$ & $.36^{* *}$ & $(.13)$ & $-.20^{*}$ & $(.04)$ \\
\hline
\end{tabular}

$* p>.05, * * p>.01$

\section{DISCUSSION}

The goal of this study was to investigate the associations among student-teachers' contact with students with disabilities (physical, developmental, and behavioral), their attitude toward students with disabilities (hopelessness, optimism, and misconceptions), and their empathic functioning (perspective taking, emotional concern, and personal distress). While little research has investigated student-teachers' attitudes and contact with students with disabilities and even less have investigated student-teachers' empathic functioning, no research to date has attempted to understand the associations among all three of these multidimensional variables.

Previous research supports the notion that increased contact with individuals with disabilities promotes more favorable attitudes toward such individuals in the general population, (Hunt and Hunt, 2000; McDougall et al., 2004; Kalyva and Agaliotis, 2009; Seo and Chen, 2009) as well as with teachers,(Harvey and Green, 1984; Tait and Purdie, 2000). The current study generally supports this notion however; the current results demonstrate that quantity of contact is not the only variable associated with positive attitudes. Empathic functioning is also associated with positive attitudes. While increased contact with students with disabilities may allow studentteachers to gain a more accurate view and a better understanding of students with disabilities, student-teachers' empathy might provide that "spark of human concern" necessary to have positive interactions and attitudes toward students with disabilities.

The first hypothesis of this study was that increased contact with students with disabilities would be associated with increased positive attitudes toward students with disabilities. Specifically, increased contact with students with physical, developmental, and behavioral disabilities would be associated with lower misconceptions, lower hopelessness, and higher optimism. The results showed that the first hypothesis was only partially supported. Increased contact with students with behavioral disabilities was associated with lower hopelessness and lower misconceptions. Increased contact with students with physical disabilities was also associated with lower misconceptions. However, all associations were weak. This pattern of results is contrary to previous research findings with a similar population,(Yuker, 1988; Tait and Purdie, 2000). However, previous research has not attempted to look at attitudes and contact with a multidimensional approach. Thus interacting with numerous students with different disabilities might not have a cumulative effect on attitudes. 
Interestingly, student-teachers majoring in special education had significantly more contact with students with developmental and behavioral disabilities but did not have more positive attitudes than student-teachers majoring in regular education did. Barr and Bracchitta (2008) showed that education majors (regular and special) who had not completed any formal field experience in their teacher preparation program had significantly more contact with individuals with disabilities as well as significantly more positive attitudes toward such individuals than noneducation majors. This demonstrates that education majors are already higher in positive attitudes and contact with individuals with disabilities than the general population. Consequently, student-teachers may have hit the ceiling of their attitudes and the short experience of student teaching might not be sufficient to affect them.

The second hypothesis of this study was that increased empathic functioning would be associated with increased positive attitudes toward students with disabilities. Specifically, increased perspective taking, increased emotional empathy, and decreased personal distress would be associated with lower misconceptions, lower hopelessness, and higher optimism. All three empathy variables were highly correlated with all three attitude variables. Such relationships have not been demonstrated in the research literature before.

Perspective taking, the cognitive aspect of empathy was related to higher optimism, lower hopelessness, and lower misconceptions. Teachers with better perspective taking would be able to take a third-person perspective, which would aid them in understanding diverse students' needs. Emotional concern, the emotional aspect of empathy was also related to higher optimism, lower hopelessness, and lower misconceptions. Teachers higher in emotional concern would be better at reacting more appropriately to student behavior and demonstrating caring for the student. Such teachers would not view the students' disability as an inconvenience or nuisance but rather encourage such students by demonstrating caring and understanding of the student's situation. Personal distress, the self-oriented anxiety aspect of empathy, was related to lower optimism, higher hopelessness, and higher misconceptions. Teachers high in personal distress will experience personal discomfort in the presence of students who require assistance or students who have additional stress themselves, thus leading to the avoidance of such students. Such teachers would find it difficult to positively interact with students with disabilities and their negative attitudes toward such students could be reflective of their own self-focused aversive feelings.

While a strong cause and effect relationship cannot be determined because of the correlational nature of this study, the results do point to the relative importance of the student teaching experience as well as empathic functioning. With more students with disabilities being educated in regular education classrooms, how should teacher-training programs go about increasing future teachers' attitudes toward students with disabilities? While most educators would agree that future teachers should be exposed to as many diverse students as possible, the results above point to an important interpersonal quality that, perhaps, may play a more vital role in shaping our future teachers' attitudes toward students with disabilities. This has an impact on how we prepare future teachers and highlights the need for empathic training that future teachers 
should engage in, beyond diverse field experiences. With teacher-training programs currently focusing on teacher dispositions, such programs need to focus more on training future teachers to recognize and exercise their empathic capacities. However, it is controversial whether empathy can be taught.

Research has shown that empathy increases with age (Eisenberg, 2006). As the individual develops from infancy to adulthood, both perspective-taking and emotional concern develop and reach adult levels while personal distress decreases (Davis and Franzoi, 1991). There is evidence that by late adolescence the cognitive capabilities that support perspective taking have finished developing (Selman, 1980). While most adults have the cognitive capability of perspective-taking, some might not have the disposition for perspective-taking. Because of this, any variability in empathy should be viewed as the propensity rather than the capacity to use those abilities. This would pose a challenge for any teacher training program since the focus of such training could not be on building capacities but rather on 1) promoting the recognition of such capacities and 2) the encouragement to use those capacities. This was highlighted in a meta-analysis of 29 articles pertaining to empathy training for teachers and other human services professionals (Lam et al., 2011). Almost all research in the meta-analysis showed positive findings concerning participants learning empathy suggesting that regardless of the training method, individuals can learn about the concept of empathy. Unfortunately, information pertaining to the effects of training on individuals' feeling for others, and their ability and propensity to take the perspective of others and to demonstrate it in the natural environments is lacking.

Effect sizes were calculated as a means of further illuminating the magnitude of associations between empathy, attitudes, and contact. Using Cohen (1988) categories of .20 as small, .50 as medium, and .80 or higher as large, all of the effect sizes in this study were small. Ferguson (2009) posited that $d=.41, r=.2$, and $R^{2}=.04$ is the recommended minimum effect sizes representing a 'practically' significant effect for social science data. Using these criteria, most effect sizes met or exceeded the recommended minimum, demonstrating practically significant effects of empathy on attitudes.

Although the present study adds to the body of literature on future teachers' attitudes toward students with disabilities, it is not without its limitations. One limitation is how contact and disability was operationalized. There are no standardized measures of contact and there is little agreement in the literature as to what constitutes contact, regardless of the population of interest. Yet, no alternative method exists to get at the aspects of contact, which require respondents' knowledge, and reporting of their own prior experiences, and for this we must continue to rely on self-reports, which suffer from systematic response bias (Sharp and Hewstone, 2010). One way to demonstrate the importance of a phenomenon is to show that the phenomenon can be detected even in the least auspicious of circumstances (Cortina and Landis, 2009). Although effect sizes were not large by traditional standards, the fact that associations were found between three broad categories of empathy and attitudes with a relatively small sample size is evidence that the effect of these relationships was very powerful. Future researchers should attempt to operationalize 
disability in more detail as the three broad categories of disability could have several subcategories within them.

Another issue in the current study was the period of time participants were asked to report their contact. While student-teaching is a 15 -week experience, the participants have had a lifetime of experiences, which have shaped their attitudes and empathic functioning. A 15-week, highly structured experience might not be sufficient to influence attitudes or empathy, which has formed over a lifetime. This points to the well-developed interpersonal reactions styles that teachers in training have when they enter teacher training programs and the challenges that teacher educators may encounter in trying to improve dispositions. In addition, without a pretest, any change in attitudes during the student-teaching experience cannot be measured.

Teacher empathy, in general, has not been studied extensively and this study was the first to investigate the relationships between student-teacher empathy and their attitudes toward students with disabilities. While the correlational nature of this research makes it impossible to establish a cause and effect relationship, the associations found can form the basis for future, causal research. This research has an impact on how we train future teachers by helping us to understand how teachers in training can meet the needs of diverse students and lends credence to the idea that teacher training programs should include empathy training as part of their curriculum.

\section{Funding: This study received no specific financial support.}

Competing Interests: The author declares that there are no conflicts of interests regarding the publication of this paper.

\section{REFERENCES}

Abbott, S. and R. McConkey, 2006. The barriers to social inclusion as perceived by people with intellectual disabilities.

Journalof Intellectual Disabilities, 10(3): 275-287.

Allport, G.W., 1954. The nature of prejudice. Reading, MA: Addison Wesley.

Antonak, R., 1982. Development and psychometric analysis of the scale of attitudes toward disabled persons. The Journal of Applied Rehabilitation Counseling, 13(2): 22-29.

Bacon, E.H. and J.B. Schultz, 1991. A survey of mainstreaming practices. Teacher Education and Special Education, 14(2): $144-149$.

Barr, J.J., 2011. The relationship between teachers' empathy and perceptions of school culture. Educational Studies, 37(3): 365-369.

Barr, J.J. and K. Bracchitta, 2008. The effects of contact with individuals with disabilities: Positive attitudes and majoring in education. The Journal of Psychology: Interdisciplinary and Applied, 142(2): 225-243.

Batson, D.C., 1991. The altruism question: Toward a social-psychological answer. Hillsdale, NJ: Lawrence Erlbaum Associates.

Bauman, S. and A. Del Rio, 2006. Preservice teachers' responses to bullying scenarios: Comparing physical, verbal, and relational bullying. Journal of Educational Psychology, 98(1): 219-231.

Berry, R.A.W., 2008. Novice teacher's conceptions of fairness in inclusion classrooms. Teaching and Teacher Education, 24(5): 1149-1159. 
Branan, J.M., 1972. Negative human interaction. Journal of Counseling Psychology, 19(1): 81-82.

Brandes, J.A. and H.M. Crowson, 2009. Predicting dispositions toward inclusion of students with disabilities: The role of conservative ideology and discomfort with disability. Social Psychology of Education, 12(2): 271-289.

Branwhite, T., 1988. The pass survey: School-based preferences of 500+ adolescent consumers. Educational Studies, 14.(2): $165-176$

Brownlee, J. and S. Carrington, 2000. Opportunities for authentic experience and reflection: A teaching programme designed to change attitudes towards disability for pre-service teachers. Support for Learning, 15(3): 99-105.

Burke, K. and C. Sutherland, 2004. Attitudes toward inclusion: Knowledge vs. Experience. Education, 125(2): 163-172.

Cohen, J., 1988. Statistical power analysis for the behavioral sciences. 2nd Edn., Hillsdale, NJ: Lawrence Erlbaum.

Conte, R., 1994. A mediational training program for parents of children with attention deficit hyperactivity disorder. Canadian Journal of Special Education, 9(3-4): 33-68.

Cook, B.G., 2004. Inclusive teachers' attitudes toward their students with disabilities: A replication and extension. The Elementary School Journal, 104(4): 307-320.

Cook, B.G., D.L. Cameron and M. Tankersley, 2007. Inclusive teachers' attitudinal ratings of their students with disabilities. Journal of Special Education, 40(4): 230-238.

Cooper, B., 2010. In search of profound empathy in learning relationships: Understanding the mathematics of moral learning environments. Journal of Moral Education, 39(1): 79-99.

Cortina, J.M. and R.S. Landis, 2009. When small effect sizes tell a big story, and when larger effect sizes don't. In C.E. Lance \& R.J. Vandenberg (Eds.), statistical and methodological myths andurban legends. New York: Routledge. pp: 287-336.

Davis, M.H., 1980. A multidimensional approach to individual differences in empathy. Catalog of Selected Documents in Psychology, 10(1): 85 .

Davis, M.H., 1983. Measuring individual differences in empathy: Evidence for a multidimensional approach. Journal of Personality \& Social Psychology, 44(1): 113-126.

Davis, M.H. and S.L. Franzoi, 1991. Stability and change in adolescent self-consciousness and empathy. Journal of Research in Personality, 25(1): 70-87.

Eisenberg, N., 1990. Prosocial development in early and mid-adolescence. In R. Montemayor, G. R. Adams, T. P. Gulotta, (Eds.), from childhood to adolescence, a transitional period. Advances in adolescent development. An annual book series. California: Sage Publication. 2.

Eisenberg, N., 2006. Prosocial behavior. In G.G. Bear \& K.M. Minke (Eds.), children's needs III: Development, prevention, andintervention. Washington, DC: National Association of School Psychologists. pp: 313-324.

Eisenberg, N. and R.A. Fabes, 1999. Emotion, emotion-related regulation, and quality of socioemotional functioning. In L. Balter\& C Tamis-LeMonda (Eds.), child psychology: A handbook of contemporary issues. New York, NY: Psychology Press. pp: 318-335.

Eisenberg, N. and P.H. Müssen, 1989. The roots of prosocial behavior in children. New York: Cambridge University Press.

Ferguson, C.J., 2009. An effect size primer: A guide for clinicians and researchers. Professional psychology. Research and Practice, 40(5): 532-538. DOI 10.1037/a0015808.

Findler, L., N. Vilchinsky and S. Werner, 2007. The multidimensional attitudes scale toward persons with disabilities. Rehabilitation Counseling Bulletin, 50(3): 166-176. DOI 10.1177/00343552070500030401. 
Fredrickson, B.L. and L.L. Carstensen, 1990. Choosing social partners: How old age and anticipated endings make people more selective. Psychology and Aging, 5(3): 335-347.

Good, T.L. and J.E. Brophy, 2000. Motivation. In T. Good \& J. Brophy (Eds.), looking in classrooms. New York, NY: Longman. pp: 217-267.

Harvey, D. and C. Green, 1984. Attitudes of New Zealand teachers, teachers in training and non-teachers toward mainstreaming. Journal of Educational Studies, 19(1): 34-44.

Hastings, R. and S. Oakford, 2003. Student teachers' attitudes towards the inclusion of children with special needs. Educational Psychology, 23(1): 87-94.

Hoffman, M.L., 2000. Empathy and moral development: Implications for caring and justice. New York: Cambridge University Press.

Hunt, B. and C. Hunt, 2000. Attitudes toward people with disabilities: A comparison of undergraduate rehabilitation and business majors. Rehabilitation Education 14(3): 269-283.

Jahoda, A. and I. Markova, 2004. Coping with social stigma: People with intellectual disabilities moving from institutions and family home. Journal of Intellectual Disability Research, 48(8): 719-729.

Jones, R.S., D. Wint and N.C. Ellis, 1990. The social effects of stereotyped behavior. Journal of Mental Deficiency Research, 34(3): 261-268.

Kalyva, E. and I. Agaliotis, 2009. Can contact affect Greek children's understanding of and attitudes towards peers with physical disabilities? European Journal of Special Needs Education, 24(2): 213-220.

Kremer, J.F. and L.L. Dietzen, 1991. Two approaches to teaching accurate empathy to undergraduates: Teacher-intensive and self-directed. Journal of College Student Development, 32(1): 69-75.

Lam, T.C.M., K. Kolomitro and F.C. Alamparambil, 2011. Empathy training: Methods, evaluation practices, and validity. Journal of MultiDisciplinary Evaluation, 7(16): 162-200.

Makas, E., 1993. Getting in touch: The relationship between contact with and attitudes towards people with disabilities.In M. Nagler (Ed.), perspectives on disability. Palo Alto, CA: Health Markets Research. pp: 121-136.

McCaughey, T.J. and D.C. Strohmer, 2005. Prototypes as an indirect measure of attitudes toward disability groups. Rehabilitation Counseling Bulletin, 48(2): 89-99. DOI 10.1177/00343552050480020301.

McDougall, J., D.J. DeWit, G. King, L.T. Miller and S. Killip, 2004. High school-aged youths attitudes toward their peers with disabilities: The role of school and student interpersonal factors. International Journal of Disability, Development, and Education, 51(3): 287-313. DOI 10.1080/1034912042000259242.

McManus, J.L., K.J. Feyes and D.A. Saucier, 2010. Contact and knowledge as predictors of attitudes toward individuals with intellectual disabilities. Journal of Social and Personal Relationships, 28(5): 579-590.

Murphy, D.M., 1996. Implications of inclusion for general and special education. Elementary School Journal, 96(5): 469493.

Pettigrew, T.F. and L.R. Tropp, 2006. A meta-analytic test of intergroup contact theory. Journal of Personality and Social Psychology, 90(5): 751-783. DOI 10.1037/0022-3514.90.5.751.

Pruett, S.R., E.J. Lee, F. Chan, M.H. Wang and F.J. Lane, 2008. Dimensionality of the contact with disabled persons scale: Results from exploratory and confirmatory factor analyses. Rehabilitation Counseling, 51(4): 210-221. DOI $10.1177 / 0034355207311310$. 
Schultz, L.H., R.L. Selman and M.D. LaRusso, 2003. The assessment of psychosocial maturity in children and adolescents: Implications for the evaluation of school-based character education programs. Journal of Researchin Character Education, 1(2): 67-87.

Scruggs, T.E. and M.A. Mastropieri, 1996. Teacher perceptions of mainstreaming/inclusion, 1958-1995: A research synthesis. Exceptional Children, 63(1): 59-75.

Selman, R.L., 1980. The growth of interpersonal understanding. New York: Academic Press.

Seo, W. and R.K. Chen, 2009. Attitudes of college students toward people with disabilities. Journal of Applied Rehabilitation Counseling, 40(4): 3-8.

Sharp, S. and M. Hewstone, 2010. Impact of context effects on attitudes and contact: Evidence of the validity of self-reports of intergroup contact. Testing, Psychometrics, Methodology in Applied Psychology, 17(1): 5-15.

Smart, J., 2008. Disability, society, and the individual. 2nd Edn., Austin, TX: ProEd.

Stewart, C., 1990. Effect of practica types in preservice adapted physical education curriculum on attitudes toward disabled populations. Journal of Teaching in Physical Education, 10(1): 76-83.

Tait, K. and N. Purdie, 2000. Attitudes toward disability: Teacher education for inclusive environments in an Australian university. International Journal of Disability, Development and Education, 47(1): 25-38.

Tettegah, S., 2007. Preservice teachers' victim empathy. Technology, Instruction, Cognitions, and Learning, 4(2): 41-68.

Tettegah, S. and C.J. Anderson, 2007. Pre-service teachers' empathy and cognitions: Statistical analysis of text data by graphical models. Contemporary Educational Psychology, 32(1): 48-82.

Thomas, A., 2001. The multidimensional character of biased perceptions of individuals with disabilities. Journal of Rehabilitation, 67(2): 3-9.

US Department of Education, 2008. Thirtieth annual report to congress on the implementation of the individuals with disabilities education act. Washington, DC: Author.

Wentzel, K.R., 1997. Student motivation in middle school: The role of perceived pedagogical caring. Journal of Educational Psychology, 89(3): 411-419.

Yoon, J.S., 2004. Predicting teacher interventions in bullying situations. Education and Treatment of Children, 27(1): $37-$ 45.

Yuker, H., 1988. The effects of contact on attitudes toward disabled persons: Some empirical generalizations. In H.Yuker (Ed.). Attitudes toward persons with disabilities.New York: Springer Publishing.

Yuker, H., 1994. Variables that influence attitudes toward people with disabilities: Conclusions from the data. Journal of Social Behavior and Personality, 9(5): 3-22.

\section{BIBLIOGRAPHY}

Lopes, J.A., I. Monteiro, V. Sil, R.B. Rutherford and M.M. Quinn, 2004.Teachers perceptions about teaching problem students in regular classrooms. Education and Treatment of Children, 27: 394-419 